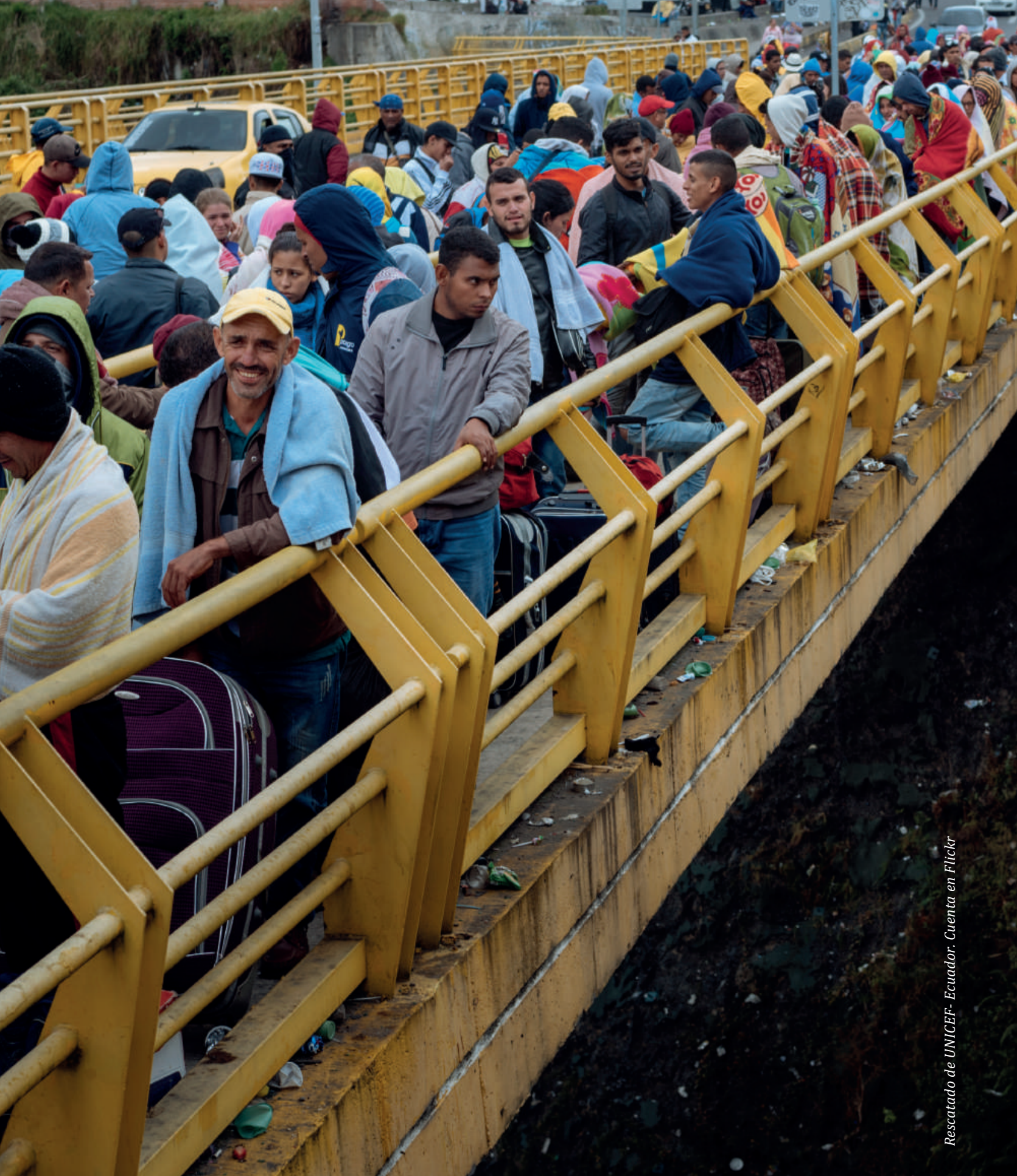




\title{
La condición del migrante irregular.Una reflexión de la noción "apátrida” desde Hannah Arendt y Giorgio Agamben*
}

\author{
Nathalia Rodríguez Cabrera** \\ María José Ovalle Román***
}

\section{Resumen}

Uno de los retos contemporáneos estatales son las migraciones masivas. Muchas de estas ocurren irregularmente, generando situaciones en donde los derechos humanos no son garantizados. El migrante irregular afronta un limbo jurídico, donde la eficaz reclamación de sus derechos humanos es comprometida por la no pertenencia real a un Estado. Hannah Arendt y Giorgio Agambem analizan cómo la consecuencia de la apatricia es la inefectividad de sus derechos humanos al no verse cobijado por un Estado garante. De ahí surge la pregunta: ¿de qué forma el migrante irregular contemporáneo se constituye en apátrida desde el diálogo existente entre Hannah Arendt y Giorgio Agamben? Para responderla, se describe cómo la decadencia del Estado-nación sirvió de antesala para el surgimiento de la apatricia y sus consecuencias; se conceptualiza la noción de migrante irregular aludiendo a su estatus jurídico, y, finalmente, se relaciona al migrante irregular contemporáneo con la noción de apátrida de Arendt y Agamben. Esto último para entender cómo el migrante irregular contemporáneo al no contar con una eficaz práctica y protección de sus derechos humanos representa el apátrida de Arendty Agamben. Este artículo es resultado de una metodología hermenéutica crítica. Palabras clave: apatricia; estado-nación; apátrida; migración irregular; derechos humanos.

\section{The condition of the irregular migrant: A reflection of the "stateless" notion from Hannah Arendt and Giorgio Agamben}

\begin{abstract}
One of the contemporary state challenges is mass migration. Many of these migrations occur irregularly, generating situations where human rights are not guaranteed. Irregular migrants face a loophole, where the successful claim of their human rights is compromised by the actual non-belonging to a State. Hannah Arendt and Giorgio Agamben analyze how the consequence of statelessness is the ineffectuality of their human rights by not being sheltered by a guarantor State. Hence the question arises: How does the contemporary irregular migrant become stateless according to the dialogue between Hannah Arendt and Giorgio Agamben? To answer this, we described how the decline of the nation-state concept served as a prelude to the emergence of statelessness and its consequences. The notion of irregular migrant is conceptualized by alluding to their legal status, and, finally, the contemporary irregular migrant is related to the notion of the stateless person according to Arendt and Agamben. In the previous argument it is important to understand how the contemporary irregular migrant, by not having an effective practice and protection of their human rights, represents the stateless person of Arendt and Agamben. All of the above is a result of the implementation of a critical hermeneutical methodology.
\end{abstract}

Keywords: statelessness; nation-state; stateless person; irregular migration; human rights.

\section{Condição do exilado ilegal Um refletir da noção "apátrida" de Hannah Arendt e Giorgio Agamben}

\section{Resumo}

Um dos desafios estaduais do momento é a migração massiva. Muitas daquelas acontecem de jeito dissonante, decorrendo numas situações nas quais os direitos humanos nem são garantidos. 0 expatriado ilegal apanha num limbo legal, onde um ressarcimento real dos seus direitos humanos é atrapalhado pelo fato de não pertencer ao Estado. Hannah Arendt e Giorgio Agamben debatem como a consequência da apatridia é a inutilidade do reconhecimento dos seus direitos humanos por não serem salvaguardados por nenhúm Estado garante. Daí surge o questionamento: como o exilado ilegal atual se torna apátrida a partir duma conversa entre Hannah Arendt e Giorgio Agamben? Para contestar, é definido como a queda do Estado-nação serviu de prelúdio ao nascimento da apatridia e as decorrentes consequências; a noção de exilado dissonante é conceituada atinente ao seu status legal e, conclusivamente, o expatriado ilegal - de hoje em dia - está vinculado à noção dos apátridas de Arendt e Agamben. Isto último, para compreender como um estrangeiro ilegal atual, por não ter uma prática nem defesa verdadeiras dos seus direitos humanos, reencarna o apátrida de Arendt e Agamben. 0 último como resultante duma metodologia hermenêutica crítica.

Palavras-chave: apatridia; estado-nação; apátrida; migração irregular; direitos humanos.

\footnotetext{
* Artículo de reflexión derivado de investigación. Se realiza en el marco del proyecto de investigación: Modelo de reintegración: giros y continuidades del discurso securitario adscrito al Grupo de investigación sobre Estudios Críticos de la Universidad Pontificia Bolivariana/Medellín.

** Abogada de la Universidad Pontificia Bolivariana, Colombia. Investigadora asociada al Grupo de investigación sobre Estudios Críticos de dicha Universidad. Correo electrónico: natalia.rodriguezcab@upb.edu.co ORCID: http://orcid. org/0000-0003-0295-2542

*** Estudiante del último año de Ciencias Políticas de la Universidad Pontificia Bolivariana, Colombia. Asistente de investigación asociada al Grupo de investigación sobre Estudios Críticos de la Universidad. Correo electrónico: maria. ovalle@upb.edu.co ORCID: http://orcid.org/0000-0003-4313-2161
}

Cómo citar este artículo: Rodríguez, N. y Ovalle, M, J. (2020). La condición del migrante irregular.Una reflexión de la nocion "apatrida" desde Hannah Arendt y Giorgio Agamben. Estudios de Derecho, 77 (169), 145-166 


\section{La condición del migrante irregular.Una reflexión de la noción "apátrida" desde Hannah Arendt y Giorgio Agamben}

\section{Introducción}

Uno de los grandes retos que los Estados contemporáneos enfrentan son las migraciones masivas desde y hacia sus territorios. Muchas de estas migraciones se dan de manera irregular, generando problemas de carácter jurídico y social en las personas o poblaciones que se ven sujetos a ellos. Se origina, entonces, una situación de exclusión, desprotección y discriminación hacia este tipo de migrante, quien, al no verse eficazmente protegido por la ley, agrava su condición de extrema vulnerabilidad. La protección de los derechos humanos de estas poblaciones, ha sido uno de los focos de trabajo de distintas organizaciones como la Comisión Interamericana de Derechos Humanos (CIDH). No obstante, el migrante irregular contemporáneo sigue condenado a un limbo jurídico donde la eficacia en la reclamación y el respeto de sus derechos humanos se ve comprometida debido a la no pertenencia de facto a un Estado.

Desde Hannah Arendt (1906-1975), precisamente, el mayor problema con las personas en condición de apátrida es la ineficacia de sus derechos al no contar con la tutela de un Estado que los garantice. En palabras más exactas, Arendt advierte que la cuestión central no es la titularidad de derechos, sino la ineficacia de estos frente a un estado de alegalidad no voluntaria del migrante irregular por su condición de apátrida. Este problema genera una especie de paradoja en el ámbito de los derechos humanos entre el deber ser frente al ser, pues la experiencia empírica, desde Arendt, supone que se descobija de su condición humana a aquellas personas que no pertenezcan jurídicamente a un Estado. Arendt (2002), entiende al apátrida como alguien que ha sido excluido al negarle la pertenencia a una comunidad.

En este mismo sentido, Giorgio Agamben, filósofo italiano -bien conocido como ávido lector de Arendt-, explica cómo la figura del apátrida es quien pone en crisis el vínculo Estado-nación-territorio, ya que, al no contar con un vínculo de ciudadanía, se encuentra en un espacio de indeterminación entre el derechoy el hecho, donde ocurre 
el abandono de la vida y su deshumanización. De esta forma, el filósofo italiano busca complementar, desde sus lecturas de Arendt, cómo la decadencia del Estado-nación tiene el apátrida como la figura central de la historia política, poniendo en dificultad el concepto original de soberanía, marcando una ruptura entre la identidad del hombre y del ciudadano, entre el nacimiento y la nacionalidad. De allí que, y a partir de la lectura paralela de ambos autores, surja la pregunta de esta composición: ¿de qué forma el migrante irregular contemporáneo se constituye en apátrida desde el diálogo existente entre Hannah Arendt y Giorgio Agamben?

Para analizar de manera precisa cómo el migrante irregular contemporáneo se puede entender como apátrida desde Arendt y Agamben, como primera instancia, se explorará el fenómeno de la decadencia del Estado-nación, que Arendt describe como aquel evento donde una nación en particular toma preponderancia dentro de la figura del Estado sobre una variedad de naciones que conviven dentro del mismo, creando de esta manera, desde su vivencia en la Segunda Guerra Mundial, la categoría de apátrida. En Arendt (2002), la figura del apátrida se presenta como la característica principal de la decadencia del Estado-nación. Retomando el análisis de la filósofa, Giorgio Agamben realiza un análisis del apátrida como una figura política central, que denota la conducta del soberano hacia una desprotección de este al no configurarse frente a él el vínculo de nacionalidad, siendo una crítica hacia el vínculo Estado-nación y su estructuración desde los derechos del hombre y el ciudadano.

Entendiendo entonces como el apátrida, desde Arendt y Agamben, resulta de la decadencia del Estado-nación se proseguirá a despejar la categoría de apátrida desde estos autores. En el caso de Arendt, esta noción se encuentra abordada especialmente en su obra: Los Orígenes del Totalitarismo (1951), específicamente, en el segundo tomo de dicha obra, donde nos enfocaremos en el noveno capítulo titulado: "La Decadencia de la Nación-Estado y el Final de los Derechos del Hombre". Es en este punto, donde Arendt elabora lo que, desde su vivencia como judía sin Estado, es un apátrida, quien está caracterizado particularmente por no tener un gobierno que lo represente y lo proteja, estando condenado a vivir, entre otras cosas, bajo la condición absoluta de ilegalidad (Arendt, 2002). Durante este capítulo, Arendt apunta a la desnacionalización como un "arma poderosa de la política totalitaria", evidenciand o de esta manera la "incapacidad constitucional de las Naciones-Estados europeas para garantizar los derechos humanos a aquellos que habían perdido los derechos nacionalmente garantizados (...)" (Arendt, 2002, pp. 394-396). En Agamben, el asunto se desarrolla, principalmente, en el ensayo Nosotros los refugiados de 1995. Quien, partiendo de la lectura de Hannah Arendt, explica su teoría frente a esta figura, su relevancia política y la paradoja misma del vínculo Estado-nación desde la declaración de los Derechos hombre y el ciudadano.

En un tercer momento, se entrará a conceptualizar la noción de migrante irregular aludiendo a su estatus político y jurídico, acudiendo a organizaciones como la CIDH, especialmente, a sus informes sobre movilidad humana. En este, se lee 
como migrantes en "situación irregular" a aquellos que hayan ingresado de forma irregular a un territorio del que no son nacionales, o que hayan permanecido en dicho territorio por más tiempo de lo autorizado (CIDH, 2015). Se hará un enfoque en aquellos que hayan entrado a dichos territorios no de forma voluntaria sino obligados por diferentes factores de sus lugares de origen, es decir, en aquellas personas que entran a un Estado foráneo ya abandonados jurídica y políticamente por su lugar de origen. En un cuarto momento, se relacionarán los conceptos de migrante irregular contemporáneo con el de apátrida de Arendt y Agamben.

El presente trabajo se desarrollará bajo una metodología hermenéutica-crítica, utilizando técnicas de recolección documental de textos científicos que desarrollen el tema, acudiendo a fuentes directas e indirectas como tesis, artículos de revista y lectores de los autores a estudiar. Se analizarán dos textos base: Los Orígenes del totalitarismo de Hannah Arendt (1951) y Nosotros los Refugiados (1995) de Giorgio Agamben, con la finalidad de develar el mensaje que contienen ambos autores en torno a la noción del apátrida, buscando, en los mismos pensadores, develar el paradigma del migrante irregular que se presenta actualmente. En este artículo, se llevará a cabo un análisis que pone en diálogo dos autores, entrelazando el análisis político y filosófico de Arendt, desde su experiencia como judía sin patria, y el análisis que realiza Agamben en la crisis de los refugiados en Europa, lo cual resulta enriquecedor para el mundo académico. De esta manera, se visibilizan las problemáticas sociales, políticas y culturales debido a la degradación que ha tenido la figura de aquel que migra de manera irregular, llevando a la desprotección de sus derechos humanos, lo que conduce a una deshumanización en los casos más extremos. He aquí la cuestión crítica.

Como resultado de lo último, se evidenciará la situación en virtud de la cual los migrantes contemporáneos en condiciones irregulares, al verse abandonados por Estados tanto de origen como de destino y viéndose sometidos a una condición de extrema vulnerabilidad, pasarán a un estado de alegalidad, esto es, fuera del marco jurídico, lo cual, afecta especialmente la eficaz reclamación y ejercicio de sus derechos humanos. La anterior ineficacia se da puesto que los marcos jurídicos existentes no resultan útiles a la hora de evitar ni manejar su estatus jurídico y político, conduciéndolos, de esta manera, a poder ser clasificados, desde Arendt y, por supuesto, desde Agamben, como apátridas.

\section{La decadencia del Estado-nación}

Para el presente artículo se hace necesario develar las perspectivas de Hannah Arendt y Giorgio Agamben en torno al paradigma Estado-nación, su surgimiento y los efectos de este alrededor de la categoría del apátrida. Ambos autores explican el paradigma desde su complejidad histórica y sus consecuencias, siendo esta una 
categoría nodular a través de la cual es posible entender los orígenes del apátrida arendtiano, cuya principal característica es el abandono sistemático del Estado y su consecuente pérdida de acción y protección de derechos humanos, que, posteriormente, Agamben acoge bajo una perspectiva moderna. Todo lo anterior para un entendimiento del papel del apátrida en un Estado moderno.

Desde estos autores el vínculo Estado-nación significa un Estado que hace de la natividad o nacimiento la base de su propia soberanía, generando la inscripción de la vida natural en el orden jurídico. El vínculo con el Estado se teje en virtud de la nacionalidad, el nacional es entonces ciudadano, acreedor de derechos y obligaciones. Desde la perspectiva de Arendt, se entenderá que en sus inicios el requisito fundamental para la creación de un Estado-nación viable, sería la homogeneidad de su población, seguido por el enraizamiento natural del suelo en donde se habita (Arendt, 2002). A partir de allí, la autora señala que la desintegración y posterior decadencia de lo que se concibe como Estado nación europeo, comenzó después de la Primera Guerra Mundial, con la aparición de aquellas minorías creadas por los tratados de paz originados de esta guerra y del movimiento creciente de refugiados creados como consecuencia de las revoluciones que la misma ocasionó (Arendt, 2002). A partir de esta problemática, se elimina el requisito de la homogeneidad poblacional, dejando un único camino para la existencia en coexistencia de los Estados naciones europeos: el reconocimiento de la pluralidad humana como receptora de protección estatal con independencia de las propiedades que la caracterizan (Arendt, 2002). De este modo, se pone en cuestionamiento la fórmula según la cual se entretejen los lazos con el Estado a partir de la nacionalidad.

En Los Orígenes del Totalitarismo, Arendt aborda la problemática de las minorías y su desprotección, lo que la lleva a un hallazgo importante: solo los nacionales podían ser ciudadanos y, únicamente, ellos podían gozar de una completa protección legal, pues en los mismos tratados de minorías se contemplaba que la protección de los no-nacionales no sería una obligación de los Estados-nación, sino de la recientemente creada Sociedad de Naciones (Arendt, 2002). Posteriormente, las políticas totalitarias europeas ${ }^{1}$ utilizaron la desnacionalización de las personas pertenecientes a minorías, tanto étnicas como culturales, como un arma política a fin de lograr sus cometidos, demostrándole al mundo de esta manera la incapacidad constitucional de las naciones-Estados europeas para garantizar los derechos humanos de las personas que habían perdido los derechos "nacionalmente garantizados" (Arendt, 2002, p. 394).

Al desnacionalizar, los Estados europeos, por medio de diferentes tratados, amontonaron y sectorizaron muchos pueblos, creando así un nuevo grupo de nacionalidades (Arendt, 2002). En palabras de Arendt (2002), estos grupos eran

Desarrolladas durante la Segunda Guerra Mundial. 
sumamente pequeños y "se hallaban demasiado dispersos para alcanzar una nacionalidad completa" (p. 398). El problema con estos tratados se manifestó cuando en la práctica solo se aplicaban a los grupos de personas que contarán con un número considerable de miembros, dejando de lado a todas las demás nacionalidades que no contaban con esta característica (Arendt, 2002). En otras palabras, aquellos tratados no solucionaban la situación de la persona en calidad de apátrida, personas sin nación que en tantos casos individuales no lograban ser acogidos por los mismos, quedando sin Estado y sin derechos que pudiesen tutelar.

Desde el análisis de Arendt, la experiencia del pueblo judío en la Segunda Guerra Mundial, evidenció que "el pueblo, sin un gobierno nacional propio, se halla privado de los derechos humanos" (Arendt, 2002, p. 399). En este orden de ideas, solo se le pueden salvaguardar los derechos humanos a aquellas naciones con un gobierno propio que los represente. Esta es, precisamente, la gran decadencia del Estado-nación a la que Arendt se refiere a lo largo del capítulo estudiado², puesto que se ubican los intereses de la nación preponderante por encima de los intereses de la población en general, ocasionado una "transformación del instrumento de la ley en un instrumento de la nación" (Arendt, 2002, p. 403). La nación triunfa sobre el Estado dejando a los que no pertenecen a la misma en un estado de desprotección absoluto, quedando roto finalmente el equilibrio entre Estado y nación. Sin este equilibrio, los derechos humanos para aquellos no pertenecientes a la nación (apátridas) se convierte, desde la perspectiva de Arendt (2002), en un "idealismo sin esperanza" (p. 395). Se entiende, entonces, que la pérdida de los derechos nacionales se identifica con la pérdida de los derechos humanos (Arendt, 2002). Esto resulta definitivo en la cuestión examinada.

Debido a esta decadencia, Arendt considera que la conformación de Estadosnación en Europa fundamentados en la pluralidad de su población, no resultan aplicables puesto que aquellas naciones que quedaron despojadas de un Estado propio se verían en un estado de desprotección resultante de la invisibilización de sus derechos fundamentales, al quedar rezagados a un estatus de minoría. Sobre esto, Arendt (como se citó en Sampedro y Lorenzo, 2016) apunta que:

Las minorías de forma activa estaban bajo la lógica de que la verdadera emancipación, la verdadera libertad, sólo se podría alcanzar con la autodeterminación de la nación; sólo en ese marco, los derechos humanos estaban garantizados, una lógica que se gestó en la Revolución Francesa". Consecuentemente, "se transformaba así el estado, pasando de ser un instrumento de la ley a ser un instrumento de la nación. La nación había conquistado al estado. El interés nacional tenía prioridad

2 Capítulo: “La Decadencia de la Nación-Estado y el Final de los Derechos del Hombre”. 
sobre la ley bastante antes de que Hitler pronunciase que "el derecho es lo que es beneficioso para el pueblo alemán”. (párr. 3)

De la misma manera, y desde su experiencia como exiliada y apátrida, Arendt examina el desarraigo estatal, territorial y las migraciones masivas forzadas de grandes grupos poblacionales, que sirven de antesala a la creación de fenómenos sociales como la apatricia y, consecuentemente, al triunfo del totalitarismo, marcando de esta manera la consecuencia principal de la decadencia del Estado-nación: la invisibilización sistemática e institucional de los grupos minoritarios que habitan dentro de los Estados modernos europeos, despojándose de esta manera de sus derechos fundamentales (Arendt, 2002). Dicha afirmación resurge con cierto dramatismo cuando el análisis se traslada hacia la problemática de los refugiados y apátridas, momento en el cual los derechos supuestamente inalienables mostraban a todas luces que solo podían ser disfrutados por los ciudadanos de las naciones más prósperas (Benente, 2017).

De la misma forma, y siguiendo esta lectura, Agamben identifica el paradigma Estado-nación como aquel que adopta la figura de la nation-nación-nacer como el fundamento propio del Estado soberano. Lo anterior implica que el vínculo de la nacionalidad proporciona cabal funcionamiento a la antigua trinidad de Estado-territorio-nación. De manera que el nacimiento vincula la vida de los individuos al Estado. Bajo este contexto, para el autor, la crisis del Estado-nación se hace evidente, cuando crecientes porciones de la humanidad fracturan esta antigua trinidad. "La novedad de nuestra época, que amenaza los fundamentos mismos de la Nación-Estado es que las crecientes porciones de la humanidad ya no pueden ser representados en su seno" (Agamben, 1995, p.115). Con esta frase, Agamben explica su pensamiento refiriéndose, específicamente, a la crisis de refugiados en Europa, lo que para el autor es un vivo ejemplo del declive del vínculo Estado-nación.

Para Agamben, lo anterior se vislumbra claramente al leer los primeros tres artículos de la Declaración de derechos del hombre y el ciudadano de 1789, donde se muestra la sinergia existente entre la nación y el Estado, al suscribir el elemento nativo en cualquier asociación política ${ }^{3}$. La ficción implícita aquí es que el nacimiento se convierte inmediatamente en nación, de tal manera que no puede haber distinción entre los dos momentos. Los derechos son atribuibles al hombre solo en la medida en que él es el presupuesto inmediato de ciudadano (Agamben, 1995).

Esta condición resulta problematizadora al momento en que surgen individuos que ponen este vínculo en tela de juicio, al no poseer nacionalidad no se

3 6. La Declaración de derechos del hombre y el ciudadano de 1789 en su artículo 3 establece que: El principio de toda Soberanía reside esencialmente en la Nación. Ningún cuerpo ni ningún individuo pueden ejercer autoridad alguna que no emane expresamente de ella. 
hacen acreedores de la protección de un Estado. En su análisis, es menester dejar de concebir las "declaraciones de derechos como simples proclamaciones de valores metajurídicos y suprahistóricos, y dar cuenta de su papel histórico en la constitución de los Estados nación" (Castro, 2008, pp. 59-60). Para el autor italiano, "las declaraciones de derechos representan la figura originaria de la inscripción de la vida natural en el orden jurídico-político del Estado nación" (Agamben, 1998, pp. 161-162). De este modo, si analizamos la Declaración de derechos del hombre y del ciudadano advertimos que es propiamente "la vida natural, es decir el puro hecho del nacimiento, lo que se presenta aquí como fuente portadora del derecho" (Agamben, 1998, pp.161).

Es por lo anterior que, si en el marco de los Estados nación modernos, la figura del refugiado o apátrida resulta tan compleja es porque "al romper la continuidad entre hombre y ciudadano, entre nacimiento y nacionalidad, ponen en crisis la ficción originaria de la soberanía moderna" (Agamben, 1998, p. 167). Luego de la Primera Guerra Mundial, el nexo nacimiento-nación comienza a disociarse, algo que puede detectarse en el número de Estados europeos que dictaron leyes de desnaturalización y desnacionalización de sus propios ciudadanos y, en la misma línea, el nazismo solo enviaba a los campos de exterminio a los judíos que antes hubiesen sido debidamente desnacionalizados (Benente, 2017). Solo fracturado el vínculo de nacionalidad se dejaba desprotegidas a poblaciones enteras, todo esto como muestra del vínculo Estado-nación y su crisis a la luz de los derechos y de personas que al no considerarse ciudadanos quedaban sin ser sujeto de los mismos.

Siguiendo tanto a Arendt como Agamben, la llegada de nuevas poblaciones empieza a desestructurar el Estado-nación, pues el migrante como nuevo poblador será el que desquicie la antigua trinidad y, por lo tanto, los fundamentos mismos del Estado-nación. Pero si sucede esta crisis es, precisamente, porque ocasiona la ruptura entre hombre y ciudadano, entre el nacimiento y la nacionalidad. Para Agamben, este migrante pone en tela de juicio el fundamento propio de la soberanía, y al no hacerse presentes, la nacionalidad ni la ciudadanía, dejan al hombre al descubierto, desamparado ante un derecho que no lo protege y un Estado que no lo reconoce.

Es así como ante el reciente incremento de poblaciones migrantes, la adopción de la nacionalidad como vínculo para el reconocimiento de derechos deja en un punto de indeterminación a estas personas. Dejando suspendidos los derechos de aquellos que no son ciudadanos de un Estado. El declive del Estado-nación es, justamente, cuando se deja por fuera de la protección estatal a individuos que no pueden ser categorizados dentro de los esquemas de la ciudadanía. De esta manera se observa cómo la decadencia del Estado-nación, para los autores referidos, origina dinámicas de poder peligrosas en términos de las relaciones de ciudadano-Estado, en tanto, los individuos que no logran constituir dicho vínculo quedan en total desprotección estatal. Lo último, generaría un estado de apatricia 
para con estos sujetos, siendo los mismos invisibilizados institucionalmente, perdiendo así su capacidad de reclamar y accionar aquellos derechos supuestamente inalienables.

\section{Los apátridas}

Durante su obra: Los Orígenes del Totalitarismo (1951), Arendt expresa claramente que la condición en la que fueron colocados los judíos durante la Segunda Guerra Mundial -entre estos, ella misma- al abandonar su Estado fue la de apátrida, consistente en la pérdida de protección por parte de sus gobiernos, lo cual, no solo se reducía a esto, sino que también despojó a la persona de toda identidad oficialmente reconocida (Arendt, 2002). A lo largo de su vida, Arendt comprende que su propia vivencia de exilio "(...) no se reduce a la separación de la tierra (...), sino más bien, al hecho de perder el derecho a tener derechos, es decir, a ser marginada de la comunidad de los hombres" (Pilatowsky, 2018, p. 66). Para Arendt, el problema central de estar en condición de apátrida no reside en la posición de ser iguales ante la ley sino en el hecho de que no existe ley alguna para ellos (Arendt, 2002).

De esta manera, la condición humana de cada persona queda reducida a la pertenencia a una comunidad, a un estatus político, en cuya ausencia se despoja al individuo de su humanidad: para Arendt (2002) "los Derechos del Hombre supuestamente inalienables, demostraron no ser aplicables (...) allí donde había personas que no parecían ser ciudadanos de un Estado soberano" (p. 426). Las personas en condición de apátrida, al quedar desprotegidos y sin ningún tipo de reconocimiento entran a un estado indefinido de alegalidad, entendida como aquello que está por fuera de todo marco jurídico. Esta circunstancia frente al apátrida es de mayor vulnerabilidad, inclusive más que la de la persona que comete un accionar que esté por fuera de la ley. Sobre esto Arendt (2002) comenta:

El mejor criterio por el que decidir si alguien se ha visto expulsado del recinto de la ley es preguntarse si se beneficiaría de la realización de un delito (...) si un pequeño robo puede mejorar al menos temporalmente, su posición legal se puede tener la seguridad de que ese individuo ha sido privado de sus derechos humanos. (p. 417)

Dentro de los Estados, las personas que cometen delitos cuentan con más derechos que el apátrida descrito por Arendt, puesto que, en teoría, cuentan con la posibilidad de ser escuchados y a un juicio justo, algo que con el despojo de una identidad oficial nacional, el apátrida no puede a acceder, reafirmando así su estatus de alegalidad (Arendt, 2002). Se comprende, entonces, que la raíz del fenómeno de la apatricia se basa en aquellos apátridas creados a partir de la Primera 
y Segunda Guerra Mundial cuya vivencia representa: "La abstracta desnudez de ser solamente humano" (Arendt, 1998, p. 249).

De la misma manera, Adriano Correia (2017) apunta en su artículo "Vida y derecho en Hannah Arendt", que los apátridas y los refugiados son en la actualidad los puntos ciegos de "de los derechos humanos qué presumidos cómo naturales, no es, sin embargo, el de quién no se decidió actuar, pero sí el de quien es impedido hacerlo" (p. 189). Desde Arendt, el fenómeno de la apatricia pone en tela de juicio la misma universalidad de los Derechos Humanos ya que el individuo al perder sus derechos positivos pierde con los mismos la capacidad de velar y hacer valer sus derechos fundamentales inalienables, por lo menos formalmente.

Desde Arendt, se puede decir, entonces, que la privación de todos los derechos humanos y la alegalidad frente al apátrida se manifiesta en tres consecuencias (Sánchez, 2015), a saber: primero, la "privación de un lugar en el mundo que haga significativas las opiniones y efectivas las acciones" (Arendt, 2002, p. 430), es decir, la privación no del derecho a la libertad sino del de acción; segundo, la privación del entramado social que solía cobijar la persona, la pérdida de un lugar en el mundo al que puedan llamar "hogar", y, por último, la pérdida de la protección de su gobierno, lo cual, no solo conlleva a la falta de un estatus legal dentro de sus fronteras sino también de un estatus legal en cualquier lugar del mundo (Arendt, 2002).

Por su parte, y teniendo en cuenta las aportaciones de Arendt, para Agamben, el apátrida resulta ser la figura central de la historia política, quien se encuentra entre el derecho y el hecho, desquiciando la antigua trinidad Estado-paísterritorio- y dando paso a lo que el autor denomina como la "nuda vida". La nuda vida o vida desnuda no es otra que la vida desprovista de toda cualificación, una vida que en principio se encontraba fuera del ordenamiento, perviviendo en un espacio de excepción donde es víctima de violencia. La "vida desnuda" es la vida en cuanto fenómeno biológica, la vida aislada, considerada solo como un trozo de materia, un elemento individual de la naturaleza que existe solamente de una manera física (Luis, 2012). Del mismo modo, y tal como acontecía con Arendt, el apátrida o refugiado es una vida simplemente humana sin un estatus que la protege, quedando fuera del ordenamiento. Agamben (2013), sostiene que en la modernidad esa "vida" es la que forma la "materia prima" de la política. Vida que parece revestirse de derechos y obligaciones, pero que, en últimas, resulta ser solo un manto que esconde una realidad ineludible, un dejamiento vil, un abandono sin remordimiento alguno.

Desde el punto de vista de Agamben, y retomando los conceptos de Jean-Luc Nancy, el apátrida se encuentra en una relación de bando, es decir, de abandono y desprotección, indicando con ello que no forma parte del cuerpo político y de un ordenamiento jurídico; puesto que es el ciudadano, quien ya no se encuentra 
en un estado natural ni puede considerarse por tanto en mero viviente, aquel que representa, en su supuesto, una vida cualificada de derechos y acogidas por el ordenamiento. De manera que, explica el autor, el ordenamiento legal pone la vida natural, la vida que no es considerada como merecedora de derecho, en bando, abandonada. Aquella vida desprotegida es representada por el apátrida, aquel que se encuentra abandonado y cuyos derechos han sido fracturados y relegados, y que, por tanto, no es más que una nuda vida.

El bando considerado como la "estructura" histórico-ontológica de la excepción soberana:

Es esencialmente el poder de entregar algo a sí mismo, es decir, el poder de mantenerse en relación con un presupuesto que está fuera de toda relación. Lo que ha sido puesto en bando es entregado a la propia separación y, al mismo tiempo, consignado a la merced de quien lo abandona, excluido e incluido, apartado y apresado a la vez. (Agamben, 2006, p. 142)

Así, pues, aquello que el bando tendría a su haber será, precisamente, la vida que, en su estar entregada a la separación, se sitúa al mismo tiempo, como excluida e incluida, apartada y apresada (Bolton, 2012). Desde este análisis, Agamben advierte que el apátrida no es simplemente excluido del ordenamiento, como bien lo había expuesto Arendt, sino apresado por el mismo, en una zona de indistinción a condición del poder y expuesta a la muerte, encontrándose en una relación que él denomina como exclusión-inclusiva. De manera que la vida desnuda (es decir, la vida excluida de toda cualidad política), haya terminado ingresando de esta forma al centro del espacio político occidental, generando una politización de la vida desnuda sin precedentes (Bolton, 2012).

Es así como desde la perspectiva agambeniana, bando vendrá a designar la estructura ontológico-política del estado de excepción, cuya característica central sería la de ser un dispositivo a través del cual el poder soberano logra capturar a la vida, en la medida que, en dicha relación, la vida queda liberada de la ley y, a la vez, apresada al poder (Bolton, 2012). Lo anterior, devela para el autor la paradoja existente según la cual, la relación originaria de la ley con la vida no sería la de su aplicación sino la del abandono (Agamben, 2006). Por ello, el "bando" como estructura ontológico-política del estado de excepción constituye un dispositivo biopolítico que incluye a la vida en el orden jurídico solo en la forma de una exclusión (Bolton, 2012).

Siguiendo esta lógica Agamben percibe en la figura del apátrida el límite en que se muestran las diversas contradicciones que vinculan el derecho con la vida humana en los Estados modernos y en la política occidental (Ruiz, 2014). En el 
apátrida $a^{4}$, es posible visualizar la forma a través de la cual el derecho amenaza la vida con su suspensión, puesto que el mismo se ve sometido a una continuada suspensión de derechos y se ve obligado a pervivir en lugares de anomia absoluta. En los campos de refugiados la vida queda excluida a un espacio donde la ley queda suspendida, un perpetuo estado de excepción donde, como dice con Hannah Arendt: "todo es posible" (Arendt, 2002). El hombre recluido en ellos es marginado de la sociedad por el propio Estado. Así al fracturar la nacionalidad como vínculo con la soberanía se expulsa la vida fuera del derecho y la captura en una zona de indistinción, donde la vida está a merced de la violencia. Poniendo en contraste ambos autores, para Arendt y Agamben el apátrida será un ser desprotegido, con un estado de alegalidad, fuera de la ley y, desde el análisis agambentiano, estará en una relación de inclusión-exclusiva, puesta en bando y víctima de violencia, será un ser humano expuesto a la muerte.

\section{El migrante irregular contemporáneo}

En su Informe sobre Movilidad Humana realizado en el año 2015, la Comisión Interamericana de Derechos Humanos define al migrante irregular como aquella persona que ha ingresado al territorio de un Estado del cual no es nacional, sin encontrarse dentro del ordenamiento jurídico migratorio del Estado receptor, o, que haya "permanecido más allá del tiempo para el cual estaban autorizados a permanecer" (CIDH, 2015b, p. 67). Se entiende, entonces, que la característica principal del migrante irregular es que al momento de ingresar a un territorio foráneo en calidad de no-nacional no se acomode a lo que conviene la ley como migración regular. La misma, estando ligada con el concepto de migración legal. De esta manera, estas personas no cuentan con un estatus jurídico ni político claramente definido dentro del Estado receptor. Debe advertirse que, aunque la condición migratoria de una persona no se acomode al ordenamiento jurídico de un Estado, no es correcto calificarlo como "persona ilegal" debido que la ilegalidad es una acción no una persona per se (CIDH, 2015b).

Por el hecho de no contar con un estatus legal claramente definido, el migrante irregular contemporáneo se ve sujeto a un estado de vulnerabilidad, viéndose obligado a vivir en la absoluta clandestinidad (CIDH, 2015b). Lo anterior, ocasionando que estas personas sean particularmente proclives a ser víctimas de violaciones a sus derechos humanos "por parte de autoridades y de particulares" (CIDH, 2015b, p. 14). Se entiende, en consecuencia, que este tipo de migrantes no

4 Para Agamben las distinciones entre refugiado y apátrida son severamente sutiles porque quien no quiere retomar o devolverse a su patria y prefiere por el contrario quedarse fuera de esta resultan sin duda ser unos "apátridas de facto" (Agamben, 1995,115). 
cuentan de facto con un Estado que les garantice su protección integral, adicionándose el temor que los mismos migrantes siente de recurrir a las instituciones estatales "por las consecuencias que esto pueda desencadenar, principalmente, el ser detenidos y posteriormente deportados" (CIDH, 2015b, p. 14). Desde Arendt, se puede interpretar lo anterior como la privación del "derecho a tener derechos", puesto que, aunque el migrante irregular todavía cuente de jure con la titularidad de sus derechos humanos, de facto no hay institución alguna capaz de garantizarlos (Arendt, 2002).

En este orden de ideas, podemos concebir como migrante irregular contemporáneo a toda persona que haya ingresado de manera no regular a un territorio del cual no se le considere nacional, cuya facultad de una eficaz reclamación y ejercicio de derechos humanos en el país que reside es casi nula, viéndose de esta manera sujeto a vivir bajo un constante estado de miedo a las diferentes instituciones estatales del país donde reside, puesto que, un paso en falso, puede significar la encarcelación o deportación (CIDH, 2015a). Por ende, dentro de esta clasificación entran, entre muchas otras, las personas en calidad de refugiados ${ }^{5}$, solicitante de asilos ${ }^{6}$, los apátridas, víctimas de trata de migrantes ${ }^{7}$ o de personas ${ }^{8}$ o, individuos que ingresen con documentos falsos a un Estado en el cual pretenden residir. Todos estos, compartiendo por supuesto, la titularidad de sus derechos humanos, pero, tal como lo advierte Arendt (2002), también comparten la falta de acción concreta sobre su protección.

La falta de acción concreta puede explicarse también por la desarticulación institucional frente al tema migratorio dentro de la normativa migratoria existente. El régimen de la migración internacional constituye una arquitectura institucional y jurídica compleja, y en ocasiones, por ende, fragmentada, particularmente en temas de cooperación internacional y el diálogo sobre cuestiones migratorias. De hecho, no existe un organismo o marco institucional único, unificado y global que tenga un mandato en materia de migración internacional (Unión Interparlamentaria, 2015). Sobre esto, el director general de 2015 de la Organización Internacional

5 “ “...) el término 'refugiado' hace relación a la persona que debido a fundados temores de ser perseguida por motivos de raza, religión, nacionalidad, pertenencia a determinado grupo social u opiniones políticas, se encuentra fuera del país de su nacionalidad; o que, careciendo de nacionalidad y hallándose, fuera del país donde tuviera su residencia habitual, no pueda o, a causa de dichos temores, no quiera regresar a él” (CIDH, 2015b, p. 68).

6 "El término 'solicitante de asilo' hace relación a la persona que solicita el reconocimiento de la condición de refugiado y cuya solicitud todavía no ha sido evaluada en forma definitiva en el país de acogida" (CIDH, 2015b, p. 69).

7 El tráfico de migrantes es "la facilitación de la entrada ilegal de una persona en un Estado Parte del cual dicha persona no sea nacional o residente permanente con el fin de obtener, directa o indirectamente, un beneficio financiero u otro beneficio de orden material" (CIDH, 2015b, p. 70).

8 "Se entenderá por trata de personas la captación, el transporte, el traslado, la acogida o recepción de personas recurriendo a la amenaza o al uso de la fuerza u otras formas de coacción, al rapto, al fraude, al engaño, al abuso de poder o de una situación de vulnerabilidad o a la concesión o recepción de pagos o beneficios para obtener el consentimiento de una persona que tenga autoridad sobre otra, con fines de explotación" (CIDH, 2015b, p. 70). 
de Trabajo (OIT), Juan Somavia, indicó que: “Lo que llama la atención en el trabajo multilateral que se lleva a cabo en el ámbito de la migración es su elevado grado de fragmentación institucional" (Unión Interparlamentaria, 2015, p. 159).

Una explicación más política sobre la falta de consenso en este ámbito, tiene que ver precisamente con la visión de que la decisión sobre quién cruza las fronteras de un Estado y sobre a quién se permite ser miembro de la sociedad de ese Estado son asuntos fundamentales de la soberanía nacional, que se vería inevitablemente socavada con una intervención multilateral en este asunto (Unión Interparlamentaria, 2015). Por lo que resulta un sistema apenas reglamentado y que cuenta con múltiples actores, que a menudo compiten entre sí, podría limitar de hecho la soberanía nacional, y que la gobernanza de la migración en el plano internacional debería ser vista como un reclamo de soberanía y no como una cesión de la misma (Unión Interparlamentaria, 2015)

Las migraciones irregulares no son un fenómeno novedoso, ya bien Arendt detectaba la situación de migraciones cuyo carácter estaba por fuera de la norma durante la Segunda Guerra Mundial (Sánchez, 2015). A estas les daban vida individuos obligados a huir de sus hogares de manera imprevista, impulsados por el miedo de ser llevados a campos de concentración donde su humanidad se vería anulada (Sánchez, 2015). Arendt interpretaba todas estas migraciones como la consecuencia directa de los gobiernos totalitarios europeos, que al haber quebrado el equilibrio entre el Estado y nación buscaban "transformar la pluralidad humana (...) en un solo hombre" (Sánchez, 2015, p. 57). En la actualidad, lamentablemente, aquellas migraciones que preveía Arendt hacen más de seis décadas continúan indiscriminadamente. Es decir, los desplazamientos transnacionales por personas que han sido desplazadas por guerras, motivos económicos, culturales, raciales, entre otros (Sánchez, 2015), constituyen la raíz de la migración irregular contemporánea.

\section{El migrante irregular: el apátrida contemporáneo}

A pesar de que Arendt no aborda la noción de migrante irregular durante su obra, sino de la condición de apátrida, puede hoy analizarse como este tipo de migrante cumple con las características a las que la alemana les asignó, hace ya 68 años a todas aquellas personas cuyas identidades oficialmente reconocidas les fueron despojadas (Arendt, 2002). Aquella similitud es, especialmente, palpable al analizar las condiciones de extrema vulnerabilidad en la que este tipo de migrantes viven en sus Estados receptores. Si bien el migrante irregular contemporáneo cuenta

9 En el año 1951, se publica Los Orígenes del Totalitarismo, cuyas páginas describen lo que Arendt concibe como un apátrida 
de jure con un Estado que los reconoce como nacionales, a diferencia del apátrida arendtiano, este mismo al migrar de manera irregular se ve privado de su derecho de acción a reclamar un eficaz respeto y garantía de sus derechos humanos (Arendt, 2002). El mismo Estado le condena a vivir en el anonimato, reduciendo su condición humana a la posesión de un estatus político (Arendt, 2002).

La Oficina del Alto comisionado de Derechos humanos de las Naciones Unidas (ACNUDH) señala que, al pasar de los años "resulta cada vez más evidente que la falta de un sistema de coordinación de la migración basado en los derechos humanos de ámbito mundial, regional y nacional" (ACNUDH, s.f., párr. 2). Lo anterior ocasiona que en la actualidad exista una profunda crisis en el ámbito de acceso a derechos fundamentales para los migrantes irregulares (ACNUDH, s.f.). En otra palabra, derechos como el acceso a la educación, a los servicios de salud y el derecho a una identidad, se convierten en figuras casi inalcanzables para estas personas (ACNUDH, s.f.). En términos de Arendt (2002) "el mismo término 'derechos humanos' se convirtió (...) en prueba de un idealismo sin esperanza o de hipocresía chapucera" (p. 395).

La violación de estos derechos "suelen estar estrechamente vinculadas a (...) prácticas discriminatorias y actitudes muy arraigadas de prejuicio y xenofobia" (ACNUDH, s.f., párr. 4). Se evidencia cómo la sociedad humana no ha superado aquellas ansias, que bien describe Arendt como una de las características de los gobiernos totalitarios europeos, de "transformar la irreductible pluralidad humana en un solo hombre, es decir, reducir la limitada pluralidad de los seres humanos (...) a un único espécimen (...)" (Sánchez, 2015, p. 57). Ejemplos de violación de derechos a migrantes irregulares no son escasos, tal como acontece con la Sentencia 168 del 2013 del Tribunal Constitucional dominicano, donde se generó la privación de la nacionalidad a todo hijo de migrante irregular nacido desde 1929 en la República Dominicana ${ }^{10}$ (CIDH, 2015a), familias centroamericanas en tránsito irregular hacia EE.UU., cuyos niños son detenidos en la frontera con México viéndose separados de sus padres por tiempos indefinidos ${ }^{11}$ (Noticias ONU, 2016), o a aquellos venezolanos que huyendo de la precaria condición social y económica de su país llegan a Colombia en busca de suplir necesidades básicas (Noticias ONU, 2018), y donde el Estado colombiano tampoco se verá en capacidad ni obligación vinculante de cumplir.

10 Esta sentencia privó "arbitrariamente de su nacionalidad dominicana a miles de personas de ascendencia haitiana (...)” (CIDH, 2015a, p. 123), ocasionando una situación de apátrida, novedosa, en nuestro continente.

11 “(...) en los primeros seis meses de 2014, más de 44,500 niños no acompañados fueron detenidos en la frontera de Estados Unidos con México; el número se redujo a casi 18,500 en el mismo periodo de 2015 y aumentó de nuevo a casi 26,000 hasta junio de 2016" (Noticias ONU, 2016, párr. 2). 
La desnacionalización en masa de la que fue testigo el mundo durante la Segunda Guerra Mundial no solo se reducía a darle muerte de la persona jurídica ${ }^{12}$ (Sánchez, 2015), es decir, a la privación del derecho a tener derechos; sino que también a eliminar a la persona moral suponiendo “(...) acabar con toda traza de solidaridad humana" (Sánchez, 2015, p. 60). De esta forma, se evitaba que las personas tuvieran acceso a la acción de reclamar sus derechos humanos; no obstante, conservándolos formalmente. El migrante irregular contemporáneo ${ }^{13}$, vive en la clandestinidad, especialmente, producto del temor a las reacciones que el respectivo Estado receptor pueda tomar en su contra. Lo anterior genera que a estas personas se les prive de su derecho de acción, viéndose sujetas a una especie de "olvido organizado" (Sánchez, 2015, p. 62), tal y como se efectuó con el apátrida judío que Arendt describe.

Desde Agamben, es posible afirmar que la figura del apátrida como migrante irregular encarna desde los conceptos previamente desarrollados a una figura de ser humano expuesta, es nuevamente una materialización de la nuda vida, insacrificable y, a la vez, expuesta a la muerte. Los refugiados o apátridas, en sus diversas versiones, son poblaciones indeseadas que deben ser controladas, vigiladas, expulsadas, incluso, en algunos casos, queda clara la expectativa política del exterminio (Ruiz, 2014). Encarnan, si se quiere, una vida abandonada, desprovista de toda cualificación y solo incluida bajo la forma de la excepción; y es por estos factores que es posible vincular íntimamente apátrida como nuda vida.

En la actualidad, se puede vislumbrar los efectos que Agamben denuncia frente a la nuda vida de los migrantes irregulares, en lugares como los grandes campos de refugiados, las zonas de espera en los aeropuertos internacionales, en zonas fronterizas etc., lugares que se convierten en espacios para la vida desnuda, expuesta y vulnerable en un umbral de indeterminación donde la tutela de los derechos se pierde entre el entramado de las máquinas burocráticas. Un caso revelador es el sucedido en República Dominicana en 2013, donde por medio de una sentencia judicial del Tribunal Constitucional, fueron expulsadas del territorio miles de personas al dictaminarse la pérdida de la nacionalidad dominicana de forma retroactiva a quienes la habían obtenido siendo migrantes de origen haitiano, lo que dejó desprotegidas a generaciones enteras de personas que habían cultivado una vida en este país, teniendo que abandonar sus hogares para ser reubicados en campamentos de desplazados en la zona fronteriza con Haití. Estos dominicanos que pertenecían a la primera, la segunda e incluso (algunos de ellos) a la tercera generación de los migrantes haitianos, se encontraron de un día para otro sin

12 Entiéndase persona jurídica como ser humano sin estatus político reconocido.
13 Descrito en el acápite anterior. 
nacionalidad, en el único país que conocen y en el que han vivido; convirtiéndose en los nuevos apátridas del siglo XXI (Louidor, 2014).

Estos campos de haitianos desnacionalizados y deportados no solo recuerdan a los campos de la Segunda Guerra, sino que además dan cuenta de una vida desnuda que ha sido excluida por el ordenamiento, pero que pervive en una zona de indistinción, siendo privadas de sus derechos y prerrogativas, siendo a su vez vulnerables y víctimas de la violencia. El apátrida como migrante irregular es entonces una figura que pone ciertamente en dificultad el concepto original de soberanía, y que, marcando una ruptura entre la identidad del hombre y del ciudadano, entre el nacimiento y la nacionalidad; siendo una materialización de la nuda vida, vida desprovista de cualificación y puesta en bando. Por lo que la figura del apátrida nos permite reflexionar las formas en las que el derecho se vincula con la vida, denunciado la paradoja existente frente a la cual aquel hombre apátrida que se haya entonces en una zona de indistinción entre el derecho y el hecho; es precisamente el hombre que se pretendía reconocer o proteger en las proclamaciones de derechos, lo cual resulta ciertamente en un contrasentido.

Cabe analizar en este punto que, ante las crisis migratorias actuales, las cifras en aumento de los refugiados en el mundo y su clara condición de precariedad ocasiona que los países se enfrentan hoy en día es una masa residente permanente de los no ciudadanos (Agamben, 1995). Tan solo hasta al año 2014 las cifras de ACNUR revelaron un "dramático aumento del desplazamiento masivo provocado por guerras y conflictos, que alcanzó una vez más niveles sin precedentes en la historia reciente" (ACNUR, 2014, p. 5). En 2014, ACNUR anunció que los desplazamientos forzosos en el mundo habían afectado ya a 51,2 millones de personas, un nivel nunca visto desde la Segunda Guerra Mundial. Doce meses después, esta cifra llegó a 59,5 millones, con un aumento de 8,3 millones de personas, durante 2014, los conflictos y la persecución obligaron a una media diaria de 42.500 personas a abandonar sus casas y buscar protección en otro lugar, dentro de las fronteras de su país o en otros países. Unos 13,9 millones de personas se convirtieron en nuevos desplazados por los conflictos o a la persecución en 2014. Entre ellos había 11 millones de nuevos desplazados dentro de las fronteras de su propio país. Los otros 2,9 millones de personas eran nuevos refugiados (ACNUR, 2014).

Las cifras de desplazamientos forzosos no muestran ningún declive a través del tiempo, para final del año 2018, ACNUR reportó que a nivel global 70,8 millones de personas se vieron desplazadas debido a la persecución, los conflictos, la violencia o las violaciones de los derechos humanos, consecuentemente, estos "números globales se situaron de nuevo en una cifra récord" (ACNUR, 2019, p. 2). De estos 70,8 millones de personas 13,6 millones son reconocidos por ACNUR como nuevos desplazados; de los cuáles 10.8 millones fueron "desplazados dentro de su país y 2.8 millones" (ACNUR, 2019, p. 2), y representan "nuevos refugiados y solicitantes de asilo" (ACNUR, 2019, p. 2). Respecto a las últimas cifras, el Alto 
Comisionado de Naciones Unidas para los Refugiados Filippo Grandi afirma que las mismas son " una nueva confirmación de la tendencia creciente a largo plazo de personas urgidas de seguridad respecto a guerras, conflictos y persecuciones" (ACNUR, 2019, p. 4). Cabe anotar, que, para el final del 2018, "lo sirios siguieron siendo la mayor comunidad de desplazados con 13 millones de personas (...), los colombianos fueron el segundo mayor grupo con 8 millones de desplazados forzosos, (...), la mayor parte de ellos (98\%) dentro de su país" (ACNUR, 2019, p. 6).

Las cifras de refugiados se sitúan con frecuencia en cifras de muertos. Los miles en botes naufragantes hacia Europa se convierten rápidamente en miles de botes de muertos vivientes, nadie los desea, los Estados los desprecian y su realidad carente de derecho y de humanidad casi es arrojada por la borda. Y es que, si bien se hacen esfuerzos para su protección, su condición de no ciudadanos se traduce para los países, en muchos casos, en un claro desprecio de personas que encarnan una carga más para el Estado y para las sociedades se traducen en casos de discriminación y xenofobia. Todo lo anterior permite, a su vez, identificar el estado de indeterminación, su posición en bando como nuda vida del apátrida que nos describe Agamben en sus textos. Posicionándose en un umbral de indeterminación entre el derecho y el hecho, fuera del ordenamiento y expuestos a la muerte violenta. Con todo lo anterior puede el apátrida ser sin duda alguna un elemento que nos ayude a pensar nuevas formas de política en donde encuentre lugar ya no el nacional sino el puro hombre sin nación.

\section{Conclusiones}

Bajo lo expuesto en este texto, podemos apreciar la manera en la que el migrante irregular cumple con las características centrales descritas como la de una persona en condición de apátrida por Hannah Arendt, encontrándose especialmente en el punto común de la pérdida del "derecho a tener derechos", de la privación del derecho de acción dentro del ámbito estatal en que residen, viéndose profundamente comprometidos el respeto y la eficacia de sus derechos humanos. El hecho de que este tipo de discriminación sistemática siga ocurriendo en la actualidad, se debe entender como un llamado las autoridades estatales a:

Combatir las expresiones de racismo y xenofobia, de formular cargos contra los perpetradores de actos de violencia o discriminación contra los migrantes y de fomentar un discurso público que promueva una mentalidad abierta a las diferencias, la aceptación de los cambios sociales y la celebración de la diversidad. (CIDH, 2013, párr. 4)

No obstante, no es solo deber de los Estados volver a incorporar a aquella persona que por diversas situaciones se vio apartada de un "mundo compartido, 
despojada de los vínculos sociales y políticos de la comunidad (...)” (Sánchez, 2015, p. 46). Se debe comprender que "todos los migrantes, en virtud de su dignidad humana, (...) se deben concebir en igualdad de condiciones que los ciudadanos, independientemente de su situación administrativa (...)" (CIDH, 2013, párr. 6), superando de esta manera la concepción del ser humano, considerado solo como aquel individuo con un estatus político claramente definido, el cual, fue objeto de estudio en la obra de Arendt.

Ahora bien, es claro que existen mecanismos de derecho internacional, como la Corte Interamericana de Derechos Humanos y demás tratados y convenios internacionales que pretenden brindar una verdadera y efectiva protección de los derechos humanos para aquellos que se encuentran en una situación tanto jurídica y social en donde se dificulta el ejercicio de estos. Lastimosamente, dichas herramientas siguen siendo tardías, no solamente por la maquinaria burocrática por la que se debe pasar para lograr acceder a estos mecanismos, sino también porque todo queda reducido a la voluntad de los Estados, quienes, de no ejecutar las órdenes judiciales o sanciones terminan por violar derechos humanos sin repercusión alguna.

Las cifras de desplazamientos forzosos no muestran ningún declive a través del tiempo, para el final del año 2018, ACNUR (2019) reportó que a nivel global “70,8 millones de personas se vieron desplazadas debido a la persecución, los conflictos, la violencia o las violaciones de los derechos humanos" (p. 2), consecuentemente, estos "números globales se situaron de nuevo en una cifra récord" (p. 2). De estos 70,8 millones de personas 13,6 millones son reconocidos por ACNUR como nuevos desplazados; de los cuáles 10.8 millones fueron "desplazados dentro de su país y 2.8 millones" (p. 2), representan, "nuevos refugiados y solicitantes de asilo" (p. 2). Respecto a las últimas cifras, el Alto Comisionado de las Naciones Unidas para los Refugiados Filippo Grandi afirma que las mismas son "una nueva confirmación de la tendencia creciente a largo plazo de personas urgidas de seguridad respecto a guerras, conflictos y persecuciones" (ACNUR, 2019, p. 4). Cabe anotar, que, para el final del 2018, "lo sirios siguieron siendo la mayor comunidad de desplazados con 13 millones de personas (...), los colombianos fueron el segundo mayor grupo con 8 millones de desplazados forzosos, (...), la mayor parte de ellos (98\%) dentro de su país" (ACNUR, 2019, p. 6).

Resulta devastador el escenario que miles de personas enfrentan en la actualidad, aquellas personas a las que el hambre y la desesperación las lleva a cultivar el anhelo de escapar de su pobre y precaria vida para vislumbrar un futuro mejor, pero a quienes se les niega siquiera soñar con tal posibilidad. La crisis hoy de los inmigrantes limita con la condición de seres humanos, pues aquellos caminantes sin hogar, sin sueño y en medio de la precariedad, son los rostros manifiestos de vidas incipientes, de vidas desnudas. Reflexionar que el vínculo Estado-nación ya no resulta suficiente y que marca la conversión del apátrida en vida desnuda, 
marca la necesidad de repensar estas categorías para una nueva vinculación que nos permite no llevar a una vida en posición de bando, abandono, sino por el contrario acogerla verdaderamente por el ordenamiento y no solo por las instituciones humanitarias que acogen la vida plena en ausencia de su protección.

\section{Referencias bibliográficas}

Agamben, G. (1995) We Refugees. Symposium: A Quarterly Journal in Modern Literatures 49 (2), 114-119.

Agamben, G. (1998). Homo Sacer, el poder soberano y la nuda vida. Valencia: PRE-TEXTOS.

Agamben, G. (2003). Estado de excepción. Homo sacer, II. Buenos Aires: Adriana Hidalgo Editora.

Agamben, G. (2006). El tiempo que resta. Madrid: Trotta.

Agencia de la ONU para los Refugiados (ACNUR). (2014). Mundo en guerra. UNHCRACNUR. Recuperado de https://www.acnur.org/fileadmin/Documentos/Publicaciones/2015/10072.pdf

Agencia de la ONU para los Refugiados (ACNUR). (2019). Tendencias globales desplazamiento forzado en 2018. UNHCR-ACNUR. Recuperado de: https://www.acnur. org/5d09c37c4.pdf

Arendt, H. (1951). Los orígenes del totalitarismo. Madrid, Taurus.

Arendt, H. (2002). La Decadencia de la Nación-Estado y el Final de los Derechos del Hombre. En H. Arendt (ed.), Los Orígenes del Totalitarismo (pp. 392-438). Madrid, España: Alianza.

Arroyo, F. (22 de abril de 2016). Giorgio Agamben: "el ciudadano es para el Estado un terrorista virtual". El país. Recuperado de https://elpais.com/cultura/2016/04/19/ babelia/1461061660_628743.html

Benente, M. (2017). El ciudadano y el refugiado en la obra de Agamben. VOXJURIS, 33(1), 89-100. Recuperado de: dialnet.unirioja.es/descarga/articulo/6058760.pdf

Bolton, K. (2012). La máquina gubernamental. Soberanía y gobierno en el pensamiento de Giorgio Agamben. Revista de filosofía política. 28, 159-193. Recuperado de https://revistas.ucm.es/index.php/RPUB/article/view/47880

Castro, E. (2008). Giorgio Agamben. Una arqueología de la potencia. Buenos Aires: Unsam.

Convención de Ginebra sobre el Estatuto de los refugiados. (1951). Convención de Ginebra sobre el Estatuto de los Refugiados.

Comisión Interamericana de Derechos Humanos (CIDH). (18 de diciembre de 2013). Los migrantes son seres humanos con derechos humanos. OAS. Recuperado de http://www.oas.org/es/cidh/prensa/Comunicados/2013/102.asp 
Comisión Interamericana de Derechos Humanos (CIDH). (31 de diciembre de 2015a). Situación de derechos humanos en República Dominicana (Doc. 45/15). OAS. Recuperado de http://www.oas.org/es/cidh/informes/pdfs/RepublicaDominicana-2015.pdf

Comisión Interamericana de Derechos Humanos (CIDH). (31 de diciembre de 2015b). Movilidad humana Estándares interamericanos (Doc. 46/15). OAS. Recuperado de http://www.oas.org/es/cidh/informes/pdfs/MovilidadHumana.pdf

Correia, A. (2017). Vida y derecho en Hannah Arendt. Eikasia: revista de filosofía, (75), 185-192. Recuperado de https://dialnet.unirioja.es/servlet/ articulo?codigo $=6799661$

Louidor, W. (15 de agosto de 2014). El drama humano que viven los dominicanos de origen haitiano. América latina en movimiento. Recuperado de https://www. alainet.org/es/active/76239

Luis. (9 de octubre de 2012). Vida desnuda [Mensaje en un blog]. Filomasnou. Recuperado de http://filomasnou.blogspot.com.co/2012/10/vida-desnuda.html

Noticias ONU. (23 de agosto de 2016). UNICEF alerta de aumento de niños detenidos en la frontera sur de Estados Unidos. News. Recuperado de https://news.un.org/ es/story/2016/08/1362991

Noticias ONU. (13 de marzo de 2018). La crisis de desplazados venezolanos "es un desastre humanitario absoluto". Recuperado de https://news.un.org/es/ story/2018/03/1429032

Oficina del Alto comisionado de Derechos humanos de las Naciones Unidas (ACNUDH) (s.f.). Migración y derechos humanos. Ohchr. Recuperado de https://ohchr.org/ SP/Issues/Migration/Pages/MigrationAndHumanRightsIndex.aspx

Pilatowsky, M. (2018). Hannah Arendt y la elaboración teórica de su propio exilio. Las Torres de Lucca: revista internacional de filosofía política, 7(12), 41-68.

Ruiz, C. B. (2014). Los refugiados, umbral ético de un nuevo derecho y una nueva política. La Revue des droits de l'homme. Revue du Centre de recherches et d'études sur les droits fondamentaux, (6). Recuperado de https://revdh.revues.org/988

Sánchez, C. (2015). Estar (políticamente) en el mundo. Barcelona, España: Bonalletra Alcompas.

Sampedro, V. y Lorenzo, A. (08 de agosto de 2016). Hanna Arendt y los refugiados: de apátridas a desplazados [Mensaje en un blog]. Público. Recuperado de https:// blogs.publico.es/el-cuarto-poder-en-red/2016/08/08/hannah-arendt-y-losrefugiados-de-apatridas-a-desplazados-ii/

Unión Interparlamentaria. (2015). Migración, derechos humanos y gobernanza. Recuperado de https://www.ohchr.org/Documents/Publications/MigrationHR_and_Governance_HR_PUB_15_3_SP.pdf 